\title{
Performance and exhaust gases of a diesel engine using different magnetic treatments of the fuel
}

\author{
R. Arias Gilart'1, M. R. B. Ungaro' , C. E. A. Rodríguez², J. F. F. Hernández ${ }^{3}$, M.C. Sofía ${ }^{1}$, and D. D. Verdecia ${ }^{1}$ \\ ${ }^{1}$ National Center for Applied Electromagnetism (CNEA), Universidad de Oriente. Santiago de Cuba, CUBA, Phone: +5354728816 \\ ${ }^{2}$ Faculty of Mechanical and Industrial Engineering, Department of Transportation. Universidad de Oriente, Santiago de Cuba, CUBA \\ ${ }^{3}$ Faculty of Chemical Engineering and Agronomy, Department of Chemical Engineering, Universidad de Oriente, Santiago de Cuba, CUBA
}

\begin{abstract}
In this research, different magnetic treatments were applied to diesel fuel using static magnetic fields of $0.36 \mathrm{~T}$ of magnetic induction. The magnetic conditioners (MCs) were installed in different positions of the fuel lines in the engine and the magnetic treatment of the diesel was also carried out before introducing it into the engine tanks. The study was conducted using a four-stroke, two-cylinder, Lister Petter (LPWS2) engine with a compression ratio of 23.5:1 and a constant engine speed of $1500 \mathrm{rpm}$. The emissions of carbon monoxide (CO), carbon dioxide $\left(\mathrm{CO}_{2}\right)$, oxygen $\left(\mathrm{O}_{2}\right)$, nitrogen oxides and the temperature of the exhaust gases and the mass consumption of fuel were measured. The highest levels of reduction were achieved with the magnetic treatments that locate the MC directly in the engine's pipes. As the number of $M C$ in the engine pipes increases, the emissions of polluting gases decrease. With the treatment that locates one $\mathrm{MC}$ in front of each injector, two $\mathrm{MC}$ at the entrance of the filter and two $\mathrm{MC}$ in the return of fuel were able to increase the $\mathrm{O}_{2}$ emissions by $6.9 \%$ and decrease the $\mathrm{CO}$ emissions in about $21.3 \%$ in the last load of the generator set. With this treatment a decrease in fuel consumption of $4.89 \%$ to $80 \%$ of engine load was obtained.
\end{abstract}

ARTICLE HISTORY

Revised: $5^{\text {th }}$ Sept 2019

Accepted: $14^{\text {th }}$ Sept 2019

\section{KEYWORDS}

Internal combustion

engines;

magnetic treatment;

magnets;

gas emissions.

\section{INTRODUCTION}

Since the first years of civilization, energy has been very important to support human activity [1]. At present, this dependence is increasing. Approximately $80 \%$ of the energy consumed in the world is produced from the burning of fossil fuels [2]. The exhaustive consumption of this type of fuel has generated adverse impacts on human health and the environment. Global warming is an imminent threat and has been caused mainly by the emission of greenhouse gases (GHG), many of these gases are generated in the combustion of fossil fuels [3]. The main polluting gases produced by combustion are: carbon dioxide $\left(\mathrm{CO}_{2}\right)$, carbon monoxide $(\mathrm{CO})$, unburned hydrocarbons $(\mathrm{HC})$, nitrogen oxides $\left(\mathrm{NO}_{\mathrm{X}}\right)$, among others [4]. Internal combustion engines (ICE) are responsible for a large part of the emissions of these gases [5].

The ICE began to develop at the end of the 19th century, following a stable and slow progress over the next several hundred years. Today, ICE are used universally for the generation of electricity, transportation, construction, agriculture and the manufacture of many materials [6]. Diesel engines are preferred by ICE manufacturers because of their high output power and thermal performance [7]. The current effects produced by global warming and air pollution together with the variations in the prices of fossil fuels, require alternative solutions to promote the reduction of specific fuel consumption and emissions of polluting gases from stationary diesel engines and diesel vehicles [8].

Various techniques have been tried to reduce the emissions of polluting gases of the ICE, including improvements in the mechanical design, but the technology of the combustion engines is over one hundred years old and has already matured [7]. Other alternatives tested focus on the modification of the fuels used in this power generating equipment. Reports have been found of the use of alternative fuels such as biofuels and their mixtures with traditional fuels $[9,10]$, the use of emulsions (either with water, with different types of alcohols, among others) [11-15], the use of additives to improve the properties of traditional fuels and biofuels (including nanoparticles) [16,17]. Other techniques include the use of different devices for exhaust gases recirculation (EGR), for selective catalytic reduction (SCR) [18], the use of equipment to give ultrasonic [19] and electrical treatments to fuels [20,21], among others.

Current studies suggest that the magnetic treatment of fuel has a positive effect on the behavior of combustion processes [6, 7,22-25] because it causes changes in some physic-chemical properties of these fluids [19,26-29]. All of them have used different types of magnetic treatments and different combustion engines in the experiments, so it is impossible to make a comparison between all these treatments reported in the literature. Ali et al. (2012) reported that locating the permanent magnets inside the fuel tank managed to increase the mileage of 10 vehicles of the Dubai Taxi Corporation by $18 \%$, as well as reducing $\mathrm{CO}$ and $\mathrm{HC}$ emissions [30]. On the other hand, Arias et al. (2016) affirm that by treating the fuel before pouring it into the engine deposits, reductions of the gas emissions of a stationary generator set operating at maximum load were achieved. In their experiments they used static magnetic fields and a magnetic induction of $0.36 \mathrm{~T}$ [31]. 
Several researchers argue that the installation of permanent magnets or magnetic conditioners (MC) in the fuel lines in the ICE increases the efficiency of combustion and helps to reduce exhaust emissions [6,7,24,32]. One of the most widespread methods is the location of the magnets in the pipes that transport the fuel, just in front of the injectors in the diesel engines [22,25,33,34]. Using this treatment in a four-stroke and single cylinder diesel engine, Raut et al. (2017) obtained a decrease in fuel consumption and increase in thermal efficiency of the engine. They used a $0.4 \mathrm{~T}$ magnetic conditioner in his experiments [25].

The magnetic treatment of the fuel has been carried out in different ways. No reports have been found of works that try to compare different magnetic treatments of the fuel in the same system, so it is not possible to decide which is the most efficient treatment decreasing fuel consumption and gas emissions. Hence, it was aimed to fill this gap partially by comparing the effects on the fuel consumption and exhaust emissions of a diesel engine using different magnetic treatments of fuel. The treatments used in the Lister Petter (LPWS2) engine included the location of MC directly on the pipes that transport the fuel in the engine and also the treatment of the diesel before introducing it into the engine tanks.

\section{METHODS AND MATERIALS}

\section{Diesel Fuel}

For the development of this research, diesel processed at the Hermanos Díaz Refinery in Santiago de Cuba was used. Some of the properties of this fuel are shown in Table 1.

Table 1. Properties of the diesel used.

\begin{tabular}{lcc}
\hline Property & Standard & Value \\
\hline Cetane Index & ASTM 4727 & 46 \\
Kinematic viscosity at $40^{\circ} \mathrm{C}\left(\mathrm{mm}^{2} / \mathrm{s}\right)$ & NC ASTM D445 & 4.6 \\
Density at $25^{\circ} \mathrm{C}\left(\mathrm{kg} / \mathrm{m}^{3}\right)$ & NC ASTM D1298 & 0.85 \\
Water content $(\%)$ & ASTM D1796 & $<0.05$ \\
\hline
\end{tabular}

\section{Magnetic Conditioners}

Magnetic conditioners constructed from Neodymium-Iron-Boron permanent magnets were used to produce the static magnetic field (Figure 1). The average magnetic induction of these conditioners was 0.36T with a deviation of $0.005 \mathrm{~T}$. A dipole configuration was used to ensure that the field induction lines are evenly distributed throughout the fuel flow area.

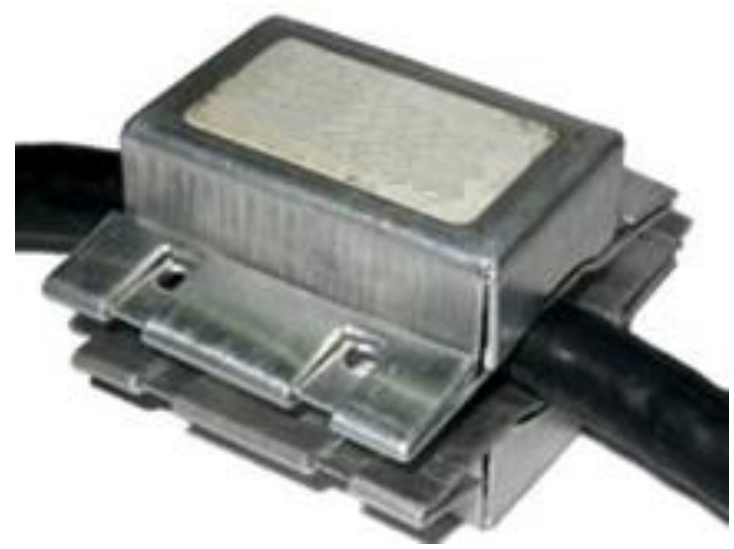

Figure 1. Magnetic conditioner.

\section{Different Magnetic Treatments}

The magnetic treatments used include the location of MC directly in the pipes that transport the fuel in the engine and also the treatment of the diesel before introducing it into the engine tanks. In addition, the operation of the engine was evaluated using Diesel without magnetic treatment (D) as the control. The different magnetic treatments used were:

- (MTD1) - Magnetic treatment of diesel before introducing it into the engine tanks. The details of this treatment can be found in the work done by Arias et al. [31,35].

- $\quad$ (MTD2) - Magnetic treatment of the diesel in the pipes that transport the diesel in the engine, placing one MC in front of each injector [22,25,33,34].

- $\quad$ (MTD3) - Magnetic treatment of diesel in the pipes that transport the diesel in the engine, placing one MC in front of each injector, two MC at the entrance of the filter and two MC in the return of fuel. No reports of similar treatments have been found in the literature. 
The different magnetic treatments, the amount of conditioners used in each one and the location of these in the motor's piping system are shown graphically in the scheme of the experimental installation (Figure 2).

\section{Experimental Engine Set-up and Procedures}

The experimental set-up used for the study of the combustion of the magnetically treated diesel is formed from a Lister Petter LPWS 2 generator. The schematic diagram of the experimental set-up used for the diesel engine tests is shown in Figure 2. To carry out the experiments, the procedure described in [31] was used, this procedure uses a stationary system in which the engine speed is kept constant and the load is varied. This type of test benches has been used with good results when analyzing changes in the type and composition of the fuel (as is the case of the use of biofuels) and when analyzing the influences of physical-chemical treatments on fuel. In addition, these systems make it possible to carry out a detailed study of the main characteristics of the engine.

The ICE of the generator set is the main element of the installation, which is a diesel engine Lister Petter LPWS2. This is a four-stroke, two-cylinder, indirect injection and water cooling engine.

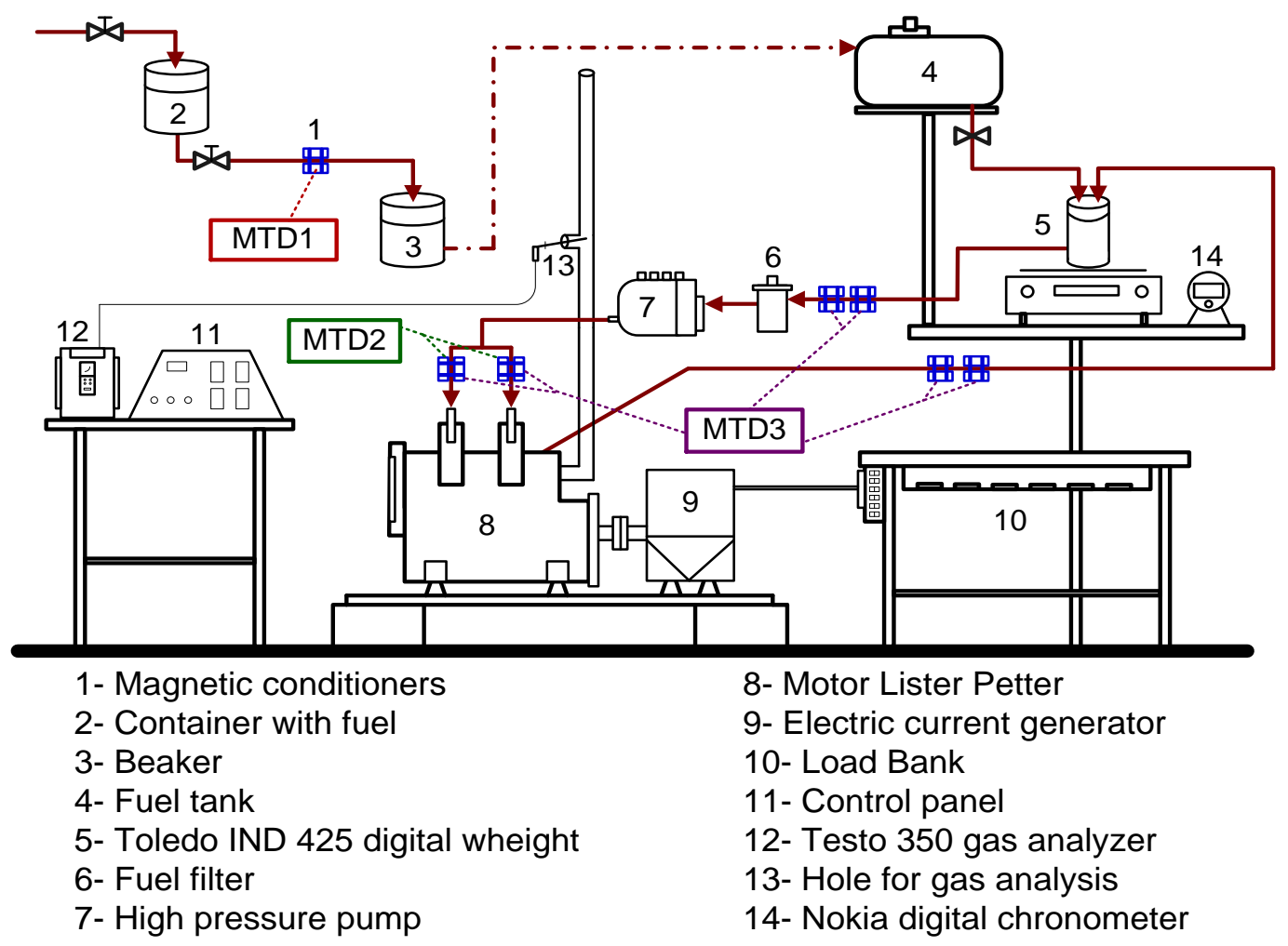

Figure 2. Schematic diagram of the experimental set-up.

The main technical characteristics of this motor are shown in Table 2. The motor has a Lister Petter current generator model BC1164D1 coupled, with a power factor of 0.86 , a voltage of $220 \mathrm{~V}$, a frequency of $50 \mathrm{~Hz}$ and a minimum speed at full load of $1500 \mathrm{rpm}$.

Table 2. Main characteristics of the Lister Petter LPWS2 engine.

\begin{tabular}{lc}
\hline Parameter & Value \\
\hline Injection type & Indirect \\
Injection pressure (bar) & $121-131$ \\
Fuel injection pump timing value at $1500 \mathrm{rpm}$ & $18^{\circ}$ before top dead center (bTDC) \\
Nominal cylinder bore (mm) & 86 \\
Stroke (mm) & 80 \\
Total cylinder capacity (L) & 0,930 \\
Compression ratio & $23.5: 1$ \\
\hline
\end{tabular}

The experiments on the engine were made with a constant engine speed of $1500 \mathrm{rpm}$, five engine loads were considered 16, 32, 48, 54 and $80 \%$. The engine of the generator set at $80 \%$ load delivers an effective power of $4.5 \mathrm{~kW}$. In these experimental conditions the variations in the mass fuel consumption (FC) and in the exhaust gas emissions of the diesel engine were analyzed. 
The mass fuel consumption was made by the gravimetric method, using a Toledo IND425 digital weight with an accuracy of $\pm 0.001 \mathrm{~kg}$ and a digital Nokia chronometer. The study of exhaust gas emissions was carried out with Testo 350 gas analyzer equipment. The gases analyzed were oxygen $\left(\mathrm{O}_{2}\right), \mathrm{CO}_{2}, \mathrm{CO}$ and $\mathrm{NO}_{\mathrm{x}}$, the temperature of the exhaust gases (TEG) was also measured. The errors involved in the experiments are calculated using uncertainty analysis which is widely followed among the researchers. Uncertainties of the measured and calculated parameters are found by using Root-sum-square method and are presented in Table 3. Using the calculation procedure, the total uncertainty for the whole experiment was \pm 4.97 .

Table 3. Uncertainties of measured and calculated parameters.

\begin{tabular}{lccc}
\hline Instrument & Range & Resolution & Uncertainty \\
\hline Toledo IND425 digital weight & $0-6 \mathrm{~kg}$ & $0.001 \mathrm{~kg}$ & 0.01 \\
Digital Nokia chronometer & $0-3600 \mathrm{~s}$ & $0.01 \mathrm{~s}$ & 0.02 \\
Mass fuel consumption & - & - & 0.01 \\
& $\mathrm{O}_{2}(0 \mathrm{a} 25 \% \mathrm{Vol})$. & $\pm 0,01 \% \mathrm{Vol}$. & 0.05 \\
& $\mathrm{CO}(0 \mathrm{a} 10000 \mathrm{ppm})$ & $\pm 1 \mathrm{ppm}$ & 2.38 \\
Testo 350 gas analyzer & $\mathrm{NO}_{\mathrm{X}}(0 \mathrm{a} 4000 \mathrm{ppm})$ & $\pm 1 \mathrm{ppm}$ & 4.31 \\
& $\mathrm{CO}_{2}(0 \mathrm{a} 50 \% \mathrm{Vol})$. & $\pm 0,01 \% \mathrm{Vol}$. & 0.04 \\
& $\mathrm{TEG}\left(0 \mathrm{a} 1000^{\circ} \mathrm{C}\right)$ & $\pm 1^{\circ} \mathrm{C}$ & 0.68 \\
\hline
\end{tabular}

For the study of gas emissions, 10 values of gas concentrations and TEG were measured for each load (five loads). To demonstrate effect of the magnetic treatment to diesel in the combustion process, three experimental runs were carried out with each treatment used and three with the diesel without magnetic treatment as the control. The experiments were carried out randomly; the temperature of the room where the motor was installed remained in the range of $30-33^{\circ} \mathrm{C}$. Error bars in the graphs are standard deviations of five replicate measurements.

\section{RESULTS AND DISCUSSION}

Generator sets generally work above $75 \%$ load because in these conditions a better performance of the motor is obtained. That is why in the comparisons made, the highest load of the analyzed engine is deepened (80\%). The results obtained with the diesel without magnetic treatment were used as a control in all analyzes carried out.

The gases analyzed were $\mathrm{O}_{2}, \mathrm{CO}_{2}, \mathrm{CO}$ and $\mathrm{NO}_{\mathrm{X}}$ because of their importance from the environmental and combustion efficiency point of view. The $\mathrm{O}_{2}$ emissions are shown in Figure 4.

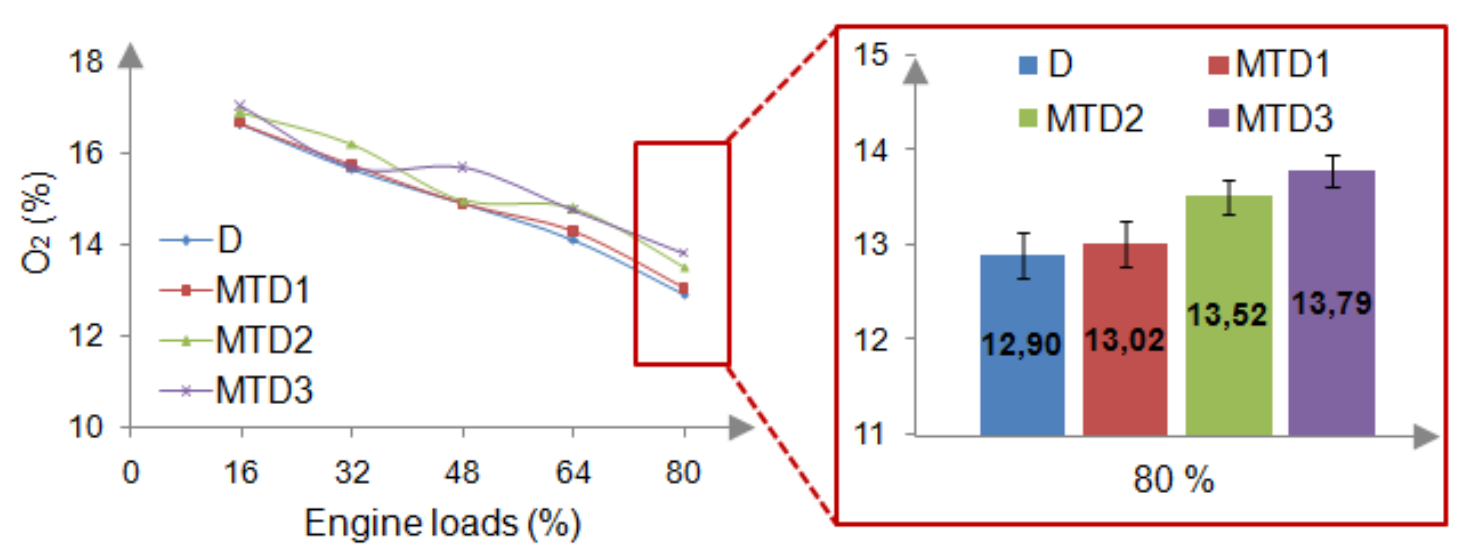

Figure 4. Behavior of $\mathrm{O}_{2}$ emissions with the different magnetic treatments.

The $\mathrm{O}_{2}$ emissions have a similar behavior with magnetically treated diesel and with untreated diesel, decrease with increasing engine load. With the treatments used, higher emissions of this non-harmful gas were obtained compared with the control diesel. At $80 \%$ load, significant differences were obtained in the $\mathrm{O}_{2}$ emissions using the magnetic treatments that include the location of MC directly in the pipes that transport the fuel in the engine (MTD2 and MTD3). By increasing the $\mathrm{MC}$ installed in the pipes that transport the motor fuel, the highest $\mathrm{O}_{2}$ emissions were achieved. With the MTD3, the last load (80\%) shows statistically significant differences, so it can be affirmed that with this type of magnetic treatment the $\mathrm{O}_{2}$ emissions of the engine are increased by $6.9 \%$.

This means that the air-fuel mixture was more efficient since less combustion $\left(\mathrm{O}_{2}\right)$ was consumed in the combustion reaction and the same results were obtained in terms of engine performance. From the environmental point of view, an increase in $\mathrm{O}_{2}$ emissions indicates a decrease in the emissions of other gases considered polluting to the environment. Similar results have not been found in the literature. Chavan et al. (2016) reported contradictory results with permanent magnets installed before the injectors and using different magnetic inductions [22]. 
Carbon dioxide $\left(\mathrm{CO}_{2}\right)$ is one of the most harmful GHGs, but it is also one of the most important products of combustion. The behaviour of $\mathrm{CO}_{2}$ emissions is presented in Figure 5.

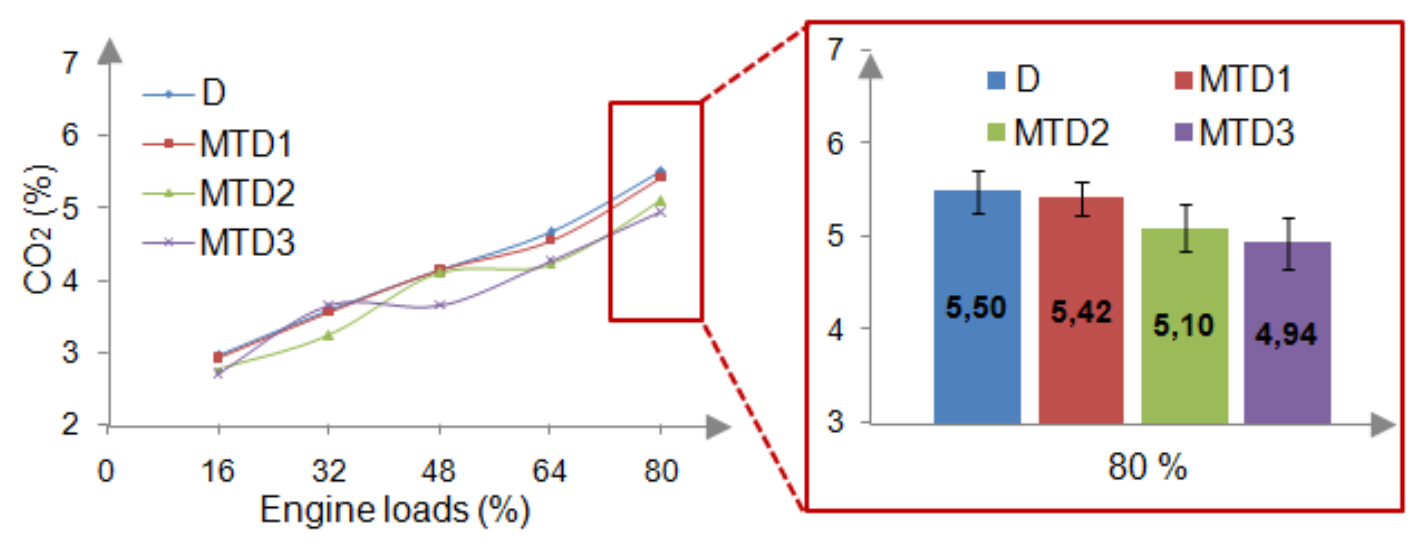

Figure 5. Behavior of $\mathrm{CO}_{2}$ emissions with the different magnetic treatments.

The comparison made, showed that $\mathrm{CO}_{2}$ emissions increase as engine loads increase, regardless of whether the fuel was magnetically treated or not. As the engine generates more power, the fuel flow that is injected into the cylinders increases and therefore $\mathrm{CO}_{2}$ emissions rise. In the largest loads the $\mathrm{CO}_{2}$ emissions obtained with the different magnetic treatments were lower than those produced with untreated diesel, the error bars reveal that there are no statistically significant differences between the $\mathrm{CO} 2$ emissions produced with the magnetically treated diesel and the control diesel. There are contradictions with the results of different researchers regarding the emissions of this gas obtained with magnetic treatment of diesel. Decreases in emissions of this gas have been reported in ranges of $9 \%$ and $2.68-4.18 \%$, using magnetic coils [33] and magnetic tubes [7] respectively for the treatment of diesel directly in the engine pipelines. However, other reports have been found with opposite results. That the case of Faris et al. (2012), they obtained an increase of $10 \%$ in the emissions of this gas produced with gasoline treated magnetically [25]. Al Khaledy (2008) obtained increases in $\mathrm{CO}_{2}$ emissions, but in this case with diesel fuel and with a magnetic induction value of 0.15T [31]. The contradictions in the results are due to the magnetic treatment systems used and the structural differences between the fuels used in the experimentation.

Among the researchers that explain the mechanism of action of magnetic fields on hydrocarbon-based fuels, we can mention Faris et al. [25]. Some of its most relevant results were achieved when permanent magnets were placed directly on the pipes that transport the fuel in the engine. They observed changes in some of the most important physical chemical properties of this type of fluid. The viscosity and density of the fuel showed significant decreases when the magnetic induction of the magnets placed in the pipes was increased.

The application of magnetic fields causes the breaking and/or weakening of some bonds in the hydrocarbons, which decreases the intermolecular attraction forces. These changes produce variations in physical chemical properties such as density, viscosity and surface tension [28, 40], as well as improving the vaporation rates and the mixing process of the fuel with the air. All of the above helps to increase the speed and efficiency of the combustion process also reduces unwanted gas emissions [25].

In the combustion process that occurs in diesel engines the chemical reaction is not complete, so that gases such as $\mathrm{CO}$ are also obtained. The behavior of the emissions of this gas obtained with the different magnetic treatments is shown in Figure 6.

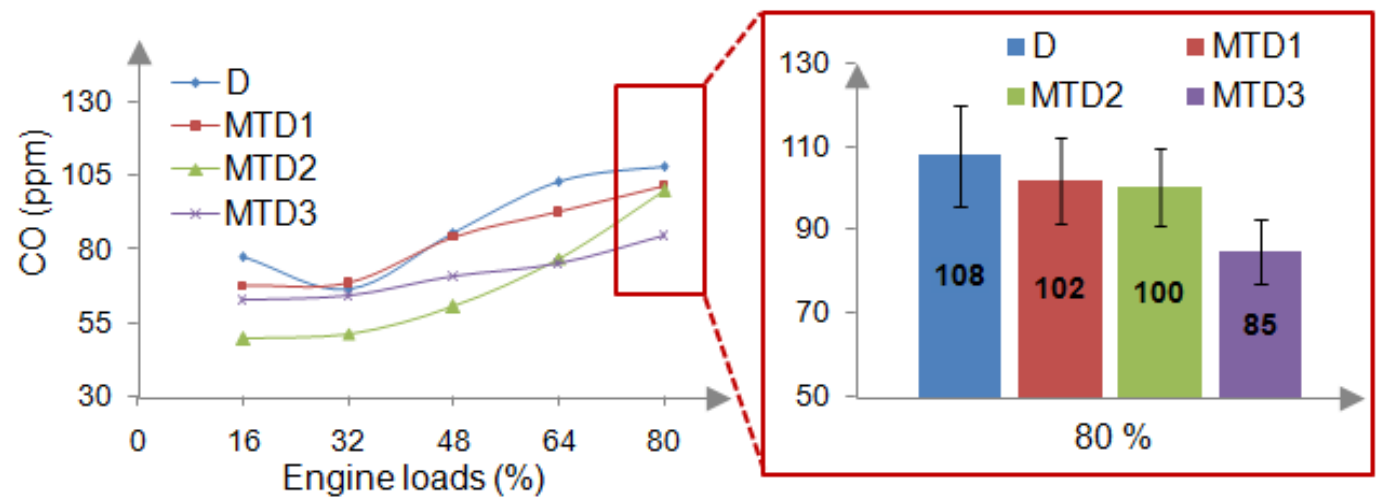

Figure 6. Behavior of $\mathrm{CO}$ emissions with the different magnetic treatments. 
In general, all the $\mathrm{CO}$ emissions achieved with the magnetically treated diesel are lower than those produced with the control diesel. At $80 \%$ load, the lower emissions of this gas were obtained with the MTD3, the processing of the data revealed that there are statistically significant differences with respect to the control diesel. The emissions of this gas were reduced by around $21.3 \%$ in the last load, so it can be affirmed that with this treatment the combustion process is improved and a more complete combustion is obtained.

The highest levels of reduction were achieved with the magnetic treatments installed by the MC directly in the engine pipes, which coincides with what was raised by Patel et al. [34], who obtained a similar behavior in the emissions of this gas using a single-cylinder diesel engine and a similar treatment to MTD2 but with a magnetic induction of $0.2 \mathrm{~T}$ [34]. Studies with analogous results regarding this gas are found in [36-38]; who obtained reductions of $13.3 \%, 7 \%$ and $8.5 \%$, respectively.

The molecules of the hydrocarbons present intermolecular attractions (sometimes caused by Van der Waals forces), these attractions cause the formation of compact structures called pseudo compounds. These are also associated to form more complex groups called clusters. This phenomenon prevents that in the combustion process the oxygen atoms can penetrate and react with the carbons present inside the clusters, producing an incomplete combustion. It also causes the formation of unburned hydrocarbons and $\mathrm{CO}$.

With the application of magnetic fields in the pipes through which the fuel flows, these associations and their cagelike structures decompose into smaller particles; which causes among other things the decrease in viscosity.

In addition, the hydrocarbons remain ionized and dispersed allowing a better penetration and reaction of oxygen, thus producing a more complete combustion inside the engine chamber [18,27,32].

It can be observed that increasing the number of magnets installed in the fuel line improve the efficiency of the combustion process of this type of internal combustion engines and it decrease the pollution gas emission. Also, the best results can be observed in high loads because test generators are more efficient at full load. These observations are consistent with measurements made by Tipole et al. [32].

Other GHG produced in the combustion processes are the $\mathrm{NO}_{\mathrm{X}}\left(\mathrm{NO}\right.$ and $\left.\mathrm{NO}_{2}\right)$. The chemical mechanism of formation of these gases during combustion processes obeys more than 100 elementary chemical reactions, depends mainly on the temperature ranges, the stoichiometric ratio and the nitrogen species present in the combustion chamber [37]. The behavior of the emissions of this gas obtained in the Lister Petter generator, applying the different magnetic treatments is shown in Figure 7.

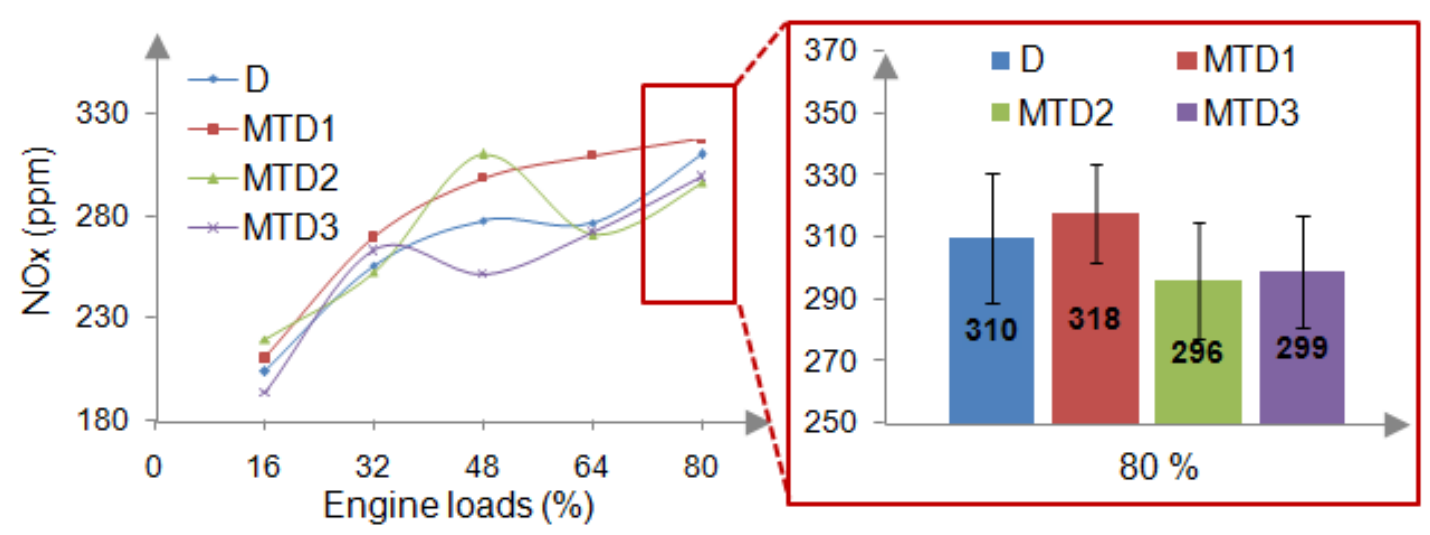

Figure 7. Behavior of $\mathrm{NO}_{\mathrm{X}}$ emissions with the different magnetic treatments.

Internal combustion engines, mainly those that work with diesel produce high quantities of NOx at high speeds and when subjected to high loads. These gases are produced due to the excess air and the high-compression ratio of this type of engines. The emissions of this gas in diesel engines are mainly due to the temperature of the gas in the post-combustion zone, the duration of these temperatures inside the chamber and the species present in the gases after combustion, being the most significant the $\mathrm{O}_{2}$ [39].

Because the combustion process is neither simple nor linear, hot spots can be found inside the chamber, which are local areas with temperatures higher than the average. The formation of these hot spots significantly affects the amount of NOx produced in the process. It is very probable that these hot spots differ each time an explosion occurs inside the combustion chambers, that is why non-linear variations in the emissions of this gas are obtained with respect to the loads and with respect to the different magnetic treatments used.

At low loads, the NOx emissions produced by the different magnetic treatments of diesel have the same behavior as the emissions generated with diesel without magnetic treatment. The graph shows that with the MTD1 treatment, greater emissions of this gas are produced. In spite of not existing statistically significant differences, in the last load the NOx emissions produced with the MTD2 and MTD3 treatments decrease of 3-4\% with respect to those produced with the untreated diesel. Similar decreases in this gas with different magnetic treatments were reported by [33] and [31]. It is speculated that this happens due to the alignment of fluid flow lines under the action of magnets, which improved 
combustion effectively causing reduction of combustion temperatures with improved oxygen-fuel ratios indicating lower NOx levels at full-load [1].

Another important parameter in the behavior of internal combustion engines is temperature of the exhaust gases. Figure 8 is shown the variation of this parameter with respect to the different magnetic treatments used.

The temperature reached by the exhaust gases at the outlet of the chamber in the engines determines the temperature reached during the combustion process [41]. The TEG increase with increasing load, similar results were obtained by [42] and [43]. The TEG does not show significant variations when using the different magnetic treatments, in some loads low values of this temperature are observed when using MTD2. When analyzing the last load (80\%) a slight decrease in this parameter is observed when magnetic treatments are used, as the error bars show, there are no statistically significant differences between the TEG values in this load. However, Cogollos et al. [38] state that the magnetic treatment of diesel fuel reduces the temperature of exhaust gases, as a result of the improvement of engine efficiency.

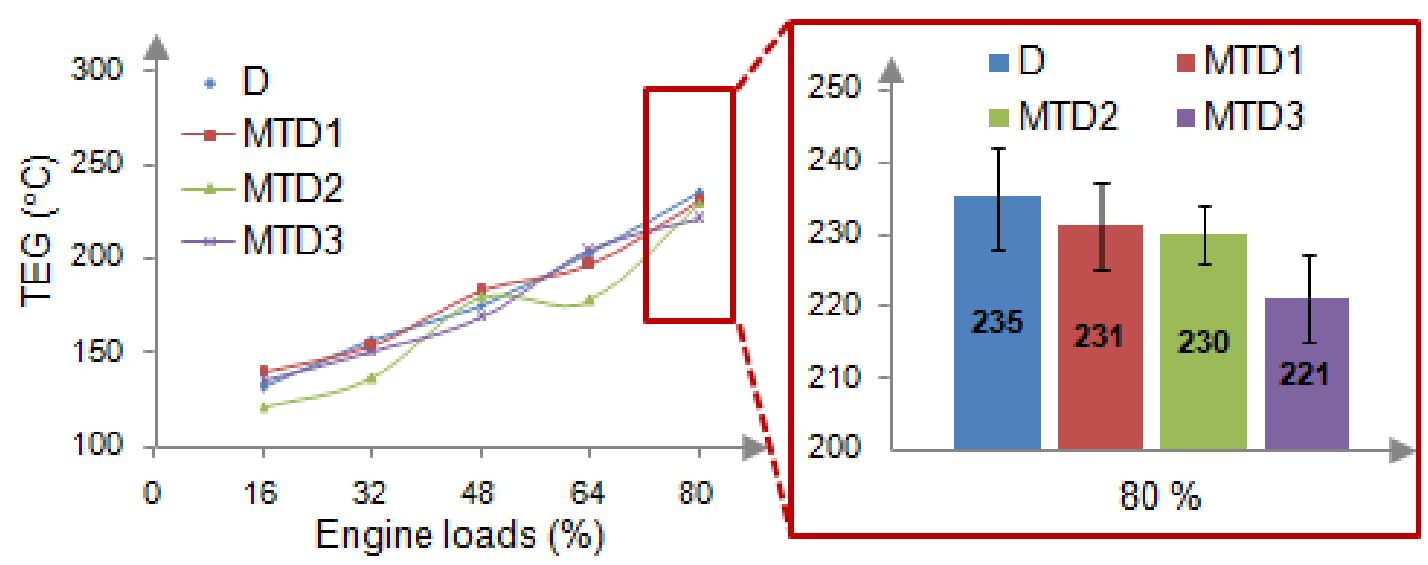

Figure 8. Behavior of TEG with the different magnetic treatments.

The increase in the thermal performance of the engine and the reduction of emissions of gases such as CO cause the combustion efficiency to increase, which should translate into a decrease in fuel consumption. The results achieved in fuel consumption from the different treatments are presented in Figure 9.

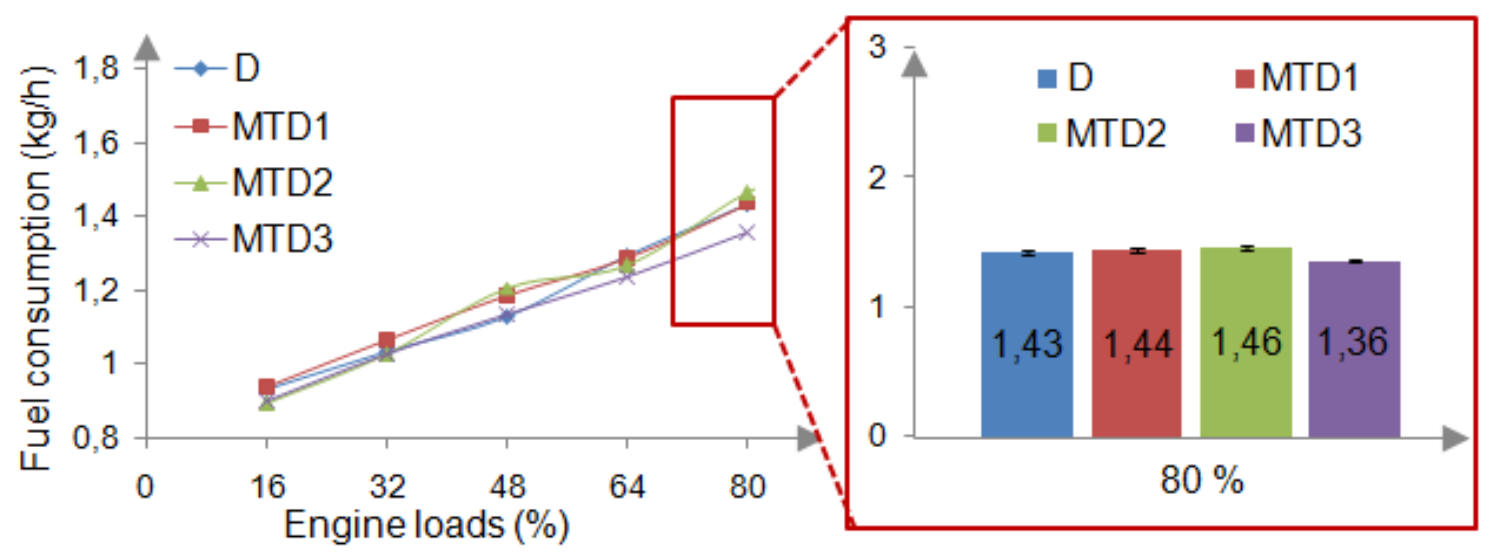

Figure 9. Behavior of fuel consumption with the different magnetic treatments.

The graph shows a similar behavior in the consumption of fuel, obtaining in some light loads increments in the consumption with respect to the diesel without magnetic treatment, this happens with the MTD1 and MTD2. The analysis performed at $80 \%$ engine load showed a statistically significant decrease in diesel fuel consumption of $4.89 \%$ with the MTD3, compared to the control. The magnitude of the reduction of specific fuel consumption depends on the magnitude of the engine load, obtaining the greatest differences in the maximum load regimes. This confirms what was stated by several researchers $[25,36,38]$ who obtained decreases of $15 \%, 4 \%$ and $14 \%$, respectively.

This happens because when the fuel is magnetically treated, the highest pressure and temperature values are obtained and inside the cylinder, closer to the top dead center, the degree of subsequent expansion being greater, and therefore increases the thermal performance of the engine, which translates into a decrease in fuel consumption [38].

Summarizing, the results obtained in the diesel engine with the application of magnetic fields can be explained due to the changes that some physical-chemical characteristics of this type of fluids undergo when crossing magnetic fields. Decreases in viscosity [26,28] and surface tension [40] have been reported, as well as the weakening of intermolecular 
bonds in this type of fluid [25]. Results have also been presented in which, with the use of magnetic fields, variations in the rheological behavior of liquid hydrocarbons have been obtained [44-46].

The best results were obtained with the application of the magnetic conditioners at the inlet of the injectors, in the return and before the fuel filter (MTD3). This is because: by applying static magnetic fields in different parts of the system, it is guaranteed that diesel fuel receives the treatment in several stages, improving the efficiency in each of the processes in which it participates. In the filter, due to the lower viscosity of the diesel due to the treatment, the hydraulic resistance decreases, this improves the efficiency of the filtering process. In the injectors, the size of the diesel drops decreases, favoring the atomization and the air-fuel mixture. In the return, longer exposure time to the magnetic field is guaranteed throughout the process.

All the above shows that the magnetic treatment of fuel, under these conditions (MTD3), can be considered as an alternative to improve efficiency in internal combustion engines, reduce the consumption of fossil fuels and emissions of polluting gases into the environment.

\section{CONCLUSIONS}

The magnetic treatments to the diesel caused changes in the combustion process of the Lister Petter LPWS2 generator set. The highest levels of reduction in emissions of polluting gases were achieved with the magnetic treatments that locate the $\mathrm{MC}$ directly in the engine pipes. As the number of $\mathrm{MC}$ in the engine pipes increases, the emissions of polluting gases decrease. With the treatment that locates an MC in front of each injector, two MC at the entrance of the filter and two MC in the return of fuel (MTD3) were able to increase the $\mathrm{O}_{2}$ emissions by $6.9 \%$ and decrease the $\mathrm{CO}$ emissions in about $21.3 \%$ in the last load of the diesel engine Lister Petter LPWS2. Although there were no statistically significant differences between the results, $\mathrm{NO}_{\mathrm{X}}$ emissions and the temperature of the exhaust gases also decreased. The MTD3 showed the lowest fuel consumption in all loads, achieving a reduction of $4.89 \%$ to $80 \%$ of engine load. So it is shown that the magnetic treatment increased the efficiency of the combustion process. The application of this new alternative (MTD3) would make possible a considerable reduction in the emissions of combustion gases, due to the high number of vehicles of this type that operate worldwide. This technology has many advantages is economic, easy to install, does not consume energy and it is not necessary to make mechanical changes in the engine. In future work we will evaluate the effectiveness of this technology using biofuels, emulsions and mixtures of different fuels. In addition, we will delve into the mechanism of action that explains the advantages obtained with the magnetic treatment of fuel.

\section{REFERENCES}

[1] Nufus TH, Setiawan RPA, Hermawan W, Tambunan AH. Characterization of biodiesel fuel and its blend after electromagnetic exposure. Cogent Engineering. 2017; 4(1):1-12.

[2] Gaurav N, Sivasankari S, Kiran G, Ninawe A, Selvin J. Utilization of bioresources for sustainable biofuels: A Review. Renewable and Sustainable Energy Reviews. 2017; 73: 205-214.

[3] Arvindnarayan S, Prabhu KKS, Shobana S, Dharmaraja J, Pasupathy A. Algal biomass energy carriers as fuels: An alternative green source. Journal of the Energy Institute. 2017; 90(2):300-315.

[4] Johnson KG, Mollenhauer K, Tschöke H. Handbook of diesel engines. New York: Springer Science \& Business Media; 2010.

[5] Boubel RW, Vallero D, Fox DL, Turner B, Stern AC. Fundamentals of air pollution. Third Edition. San Diego: Elsevier; 2013.

[6] Abdul WHA, Al-Kayiem HH, A. Aziz AR, Nasif MS. Survey of invest fuel magnetization in developing internal combustion engine characteristics. Renewable and Sustainable Energy Reviews. 2017; 79: 1392-1399.

[7] Chen C-Y, Lee W-J, Mwangi JK, Wang L-C, Lu J-H. Impact of Magnetic Tube on Pollutant Emissions from the Diesel Engine. Aerosol and Air Quality Research. 2017; 17(4):1097-1104.

[8] Zannis TC, Hountalas DT, Papagiannakis RG. Experimental study of diesel fuel effects on direct injection (DI) diesel engine performance and pollutant emissions. Energy \& fuels. 2007; 21(5):2642-2654.

[9] Pérez SA, Montero A, Gisela, Ayala BR, Coronado OMA, Campbell RHE, García GC. Simulación en Aspen de la combustión de mezclas diesel-biodiesel. Ingeniería, investigación y tecnología. 2015; 16(1):83-92.

[10] Saladini F, Patrizi N, Pulselli FM, Marchettini N, Bastianoni S. Guidelines for emergy evaluation of first, second and third generation biofuels. Renewable and Sustainable Energy Reviews. 2016; 66: 221-227.

[11] Karavalakis G, Durbin TD, Shrivastava M, Zheng Z, Villela M, Jung H. Impacts of ethanol fuel level on emissions of regulated and unregulated pollutants from a fleet of gasoline light-duty vehicles. Fuel 2012; 93: 549-558.

[12] Melo EEA, Sánchez BY, Ferrer FN, Ferrer FN. Evaluación de un motor de encendido por chispa trabajando con mezclas etanolgasolina. Ingeniería Energética. 2012; 33(2):94-102.

[13] Solmaz H. Combustion, performance and emission characteristics of fusel oil in a spark ignition engine. Fuel Processing Technology. 2015; 133: 20-28.

[19] Melo EA, Piloto RR, Sierens R, Verhelst S. Emulsification of waste cooking oils and fatty acid distillates as diesel engine fuels: An attractive alternative. International Journal of Sustainable Energy Planning and Management. 2016; 9: 3-16.

[20] Piloto RR, Sánchez BY, Melo EEA, Verhelst S. Assessment of diesel engine performance when fueled with biodiesel from algae and microalgae: An overview. Renewable and Sustainable Energy Reviews. 2017; 69: 833-842. 
[21] Devarajan Y, Munuswamy DB, Mahalingam AP. Performance, combustion and emission analysis on the effect of ferrofluid on neat biodiesel. Process Safety and Environmental Protection. 2017; 111: 283-291.

[22] Karthik N, Xavier XG, Rajasekar R, Bairavan PG, Dhanseelan S. Experimental Investigation of Performance and emission characteristics of Various Nano Particles with Bio-Diesel blend on Di Diesel Engine. In: IOP Conference Series: Materials Science and Engineering. 012014, 2017.

[23] Govindasamy P, Dhandapani S. Effects of EGR \& Magnetic Fuel Treatment System on Engine Emission Characteristics in A Bio Fuel Engine. In: Proceedings of the International Conference on Mechanical Engineering. Bangladesh; 26-28, 2009.

[24] Fedorchak V, Fedorchak T. Analysis and classification of physical and chemical methods of fuel activation. Ovidius University Annals of Chemistry. 2015; 26(2):67-73.

[25] Tao R, Huang K, Tang H, Bell D. Electrorheology improves engine efficiency. In: Journal of Physics: Conference Series. 1230, 2009.

[26] Du E, Tang H, Huang K, Tao R. Reducing the viscosity of diesel fuel with electrorheological effect. Journal of Intelligent Material Systems and Structures. 2011; 22(15):1713-1716.

[27] Chavan MS, Jhavar MP. Effect of Application of Magnetic Field on Emission of Petrol Engine. Imperial Journal of Interdisciplinary Research. 2016; 2(10):2121-2128.

[28] Petkar NN, Khamkar PK. Performance and emission analysis of magnetic fuel energizer for motorcycles. Int. J. Adv. Res. ScI. Eng. Technol. 2016; 5:300-306.

[29] Nilesh WT, Tushar AK, Patil VH. A review on effect of magnetic field to improve fuel consumption in S.I. Engine. In: National Conference on Current Trends in Engineering, Science, Technology and Management (NACCTESTM-2017). Jalgaon-India; 2017:345-349.

[30] Raut MS, Uparwat SS, Nagarale C. Experimental Inspection by using the Effect of Magnetic Field on the Performance of Diesel Engine. International Research Journal of Engineering and Technology (IRJET). 2017; 4(3):2191-2194.

[31] Hasegawa M, Mukohara S, Tachiban Y. Influence of magnetic field on kinematic viscosity of fuel oil. In: 8th Int Symp on Alcohol Fuels. 1988.

[32] Faris AS, Al-Naseri SK, Jamal N, Isse R, Abed M, Fouad Z, Kazim A, Reheem N, Chaloob A, Mohammad H. Effects of Magnetic Field on Fuel Consumption and Exhaust Emissions in Two-Stroke Engine. Energy Procedia. 2012; 18: 327-338.

[33] Aktar AR, Tipole P, Bhojwani V, Deshmukh S. Effect of magnetic field strength on hydrocarbon fuel viscosity and engine performance. IJMCA 2013; 1(7):094-098.

[34] Calabrò E, Magazù S. FTIR Spectroscopy analysis of molecular vibrations in gasoline fuel under $200 \mathrm{mT}$ static magnetic field highlighted structural changes of hydrocarbons chains. Petroleum Science and Technology. 2015; 33(19):1676-1684.

[35] Al Ali Y, Hrairi M, Al Kattan I. Potential for improving vehicle fuel efficiency and reducing the environmental pollution via fuel ionization. International Journal of Environmental Science and Technology. 2012; 9(3):495-502.

[36] Arias GR, Berenguer UM, Vázquez NJA, Silveira FY, Alfaro RCE. Reducción de las emisiones gaseosas de un grupo electrógeno con tratamiento magnético al combustible Cuba: Medio Ambiente y Desarrollo. 2016; 30:1-7.

[37] Tipole P, Karthikeyan A, Bhojwani V, Deshmukh S, Babar H, Tipole B. Reduction in the exhaust emissions of four-stroke multi-cylinder SI Engine on application of multiple pairs of magnets. International Journal of Ambient Energy. 2017; 29(8):1 7.

[38] Al-Khaledy AAJ. High performance and low pollutant emissions from a treated diesel fuel using a magnetic field. Al-Qudsiya Journal for Engineering Sciences. 2008; 1(2):211-224.

[39] Patel PM, Rathod GP, Patel TM. Effect of magnetic field on performance and emission of single cylinder four stroke diesel engine. IOSRJEN 2014; 4(5):28-34.

[40] Arias GR, Berenguer UM, Vázquez NJA, Silveira FY, Alfaro RCE. Disminución de las emisiones de monóxido de carbono con el tratamiento magnético del combustible Centro Azúcar. 2018; 45(1):21-31.

[41] Govindasamy P, Dhandapani S. Experimental investigation of cyclic variation of combustion parameters in catalytically activated and magnetically energized two-stroke SI engine. Journal of Energy \& Environment. 2007; 6: 45-59.

[42] El Fatih F, Saber G. Effect of fuel magnetism on engine performance and emissions. Australian Journal of Basic and Applied Sciences. 2010; 4(2):6354-6358.

[43] Cogollos JB, Vega JRF, Medina AS, Morales GBC. Influencia del tratamiento magnético en los parámetros de salida del motor D-65. Centro Azúcar. 2000; 27(1): 19-25.

[44] Keating EL. Applied combustion. Second Edition New York: CRC press Taylor \& Francis Group; 2007.

[45] Arias GR, Silveira FY, Campos SM, Falcón HJ. Efecto de un campo magnético estático en la tensión superficial del diésel y su atomización Revista Iberoamericana de Ingeniería Mecánica. 2018; 22(1):9-21.

[46] Bhaskar K, Sendilvelan S. Experimental studies on the performance and emission characteristics of a compression ignition engine fuelled with jatropha oil methyl ester. Journal of Mechanical Engineering and Sciences. 2018; 12(1): 3431-3450.

[47] Yusop A, Mamat R, Mat Yasin M, Ali OM. Effects of particulate matter emissions of diesel engine using diesel-methanol blends. Journal of Mechanical Engineering and Sciences. 2014; 6:959-967.

[48] Bhaskar K, Sendilvelan S, Muthu V, Aravindraj S. Performance and emission characteristics of compression ignition engine using methyl ester blends of jatropha and fish oil. Journal of Mechanical Engineering and Sciences. 2016; 10(2):1994-2007. 
[49] Loskutov YV, Yudina N. Rheological behavior of oils in a magnetic field. Journal of Engineering Physics and Thermophysics. 2006; 79(1):105-113.

[50] Arias GR, Falcón HJ, Campos SM, Silveira FY, López GÓ. Efecto del tratamiento magnético en el comportamiento reológico del diésel. Revista Tecnología Química. 2018; 38(2):412-427.

[51] Campos SM, Moro MA, Silveira FY. Comportamiento reológico de emulsiones de agua en petróleo (w/o) tratadas magnéticamente. Tecnología Química. 2018; 38(1):58-70. 